\title{
Congenital glaucoma
}

INSERM

\section{Source}

INSERM. (1999). Orphanet: an online rare disease and orphan drug data base. Congenital glaucoma. ORPHA:98976

Congenital glaucoma (CG) is a developmental glaucoma that results from the abnormal development of the aqueous drainage structure, characterized by an elevated intraocular pressure, enlargement of globe (buphthalmos), corneal edema and optic nerve cupping, and presenting clinically with the characteristic triad of epiphora, photophobia and blepharospasm. 